\title{
Influence of Long Boreholes Layout and Drilling Length on Gas Drainage Based on Multifield Coupling Model of Gas-Bearing Coal
}

\author{
Renjun Feng (iD) $1,2,3,4$ \\ ${ }^{1}$ School of Resource \& Environment and Safety Engineering, Hunan University of Science and Technology, Xiangtan 411201, \\ Hunan, China \\ ${ }^{2}$ Work Safety Key Lab on Prevention and Control of Gas and Roof Disasters for Southern Coal Mines, \\ Hunan University of Science and Technology, Xiangtan 411201, Hunan, China \\ ${ }^{3}$ State Key Laboratory of Gas Disaster Detecting, Preventing and Emergency Controlling, Chongqing 400037, China \\ ${ }^{4}$ China Coal Technology Engineering Group Chongqing Research Institute, Chongqing 400037, China
}

Correspondence should be addressed to Renjun Feng; fenrenjun2025@163.com

Received 20 June 2021; Revised 28 August 2021; Accepted 9 October 2021; Published 17 November 2021

Academic Editor: ZOU Quanle

Copyright ( 2021 Renjun Feng. This is an open access article distributed under the Creative Commons Attribution License, which permits unrestricted use, distribution, and reproduction in any medium, provided the original work is properly cited.

\begin{abstract}
Gas drainage through long seam boreholes is an effective method to prevent gas disasters in coal mines. In this paper, a multifield coupling model of gas migration in gas-bearing coal was first established. Then, a quantitative characterization method of gas drainage effect was put forward. Finally, the extraction effect of long boreholes was obtained under different layouts and drilling lengths. The research results show that, under the arrangement of long boreholes along the seam, the gas pressure around the borehole decreases significantly with the extraction time. There is no extraction blank in the middle of the working face. However, it is easy to cause uneven gas drainage in the combined arrangement of the long boreholes along the seam and the penetrating boreholes. Furthermore, it is found that the drainage volume of the long boreholes along the seam is similar to that of the joint layout under the same drainage time. As the length of the borehole increases, the influencing range of gas drainage increases. When the borehole lengths are $150 \mathrm{~m}$ and $240 \mathrm{~m}$, the drainage volumes are about 1.31 and 2.50 times that of the $90 \mathrm{~m}$ boreholes, respectively. The research achievements could provide a specific reference for the layout of long boreholes along the bedding and the determination of reasonable parameters for gas drainage on site.
\end{abstract}

\section{Introduction}

Gas drainage is an effective way to eliminate the danger of coal and gas outbursts in China at present [1-4]. In recent years, with the development of drilling rig equipment and drilling technology, gas drainage technology with long boreholes has made rapid progress [5-7]. Gas migration significantly affects the gas drainage effect of long boreholes. Therefore, a correct understanding of the law of coal gas migration is of great significance for preventing and controlling coal mine gas disasters and promoting long drilling technology [8-12].

At present, many scholars have studied the multifield coupling model of coal seam gas migration. The coal reservoir is a typical double pore system composed of interlaced fractures and coal matrices [13-15]. Coal seam gas migration mainly includes two processes: diffusion and seepage. First, the gas is desorbed from the coal matrix and diffused into the fissures under the action of a concentration gradient. This process conforms to Fick's law of diffusion. Then, the gas in the fissure flows to the borehole under the action of the pressure gradient, and this process conforms to Darcy's law [16]. Su et al. [17] described a dual pore model that paralleled coal seam gas migration. The diffusion and seepage of gas in gas drainage are simulated, and the influence of diffusion coefficient on gas pressure evolution and permeability in fractures is analyzed. Dong et al. [18] analyzed the mechanism of negative pressure in gas drainage through a gassolid coupling model and put forward a method to reduce the negative pressure of drainage to improve gas drainage efficiency. Mora and Wattenbarger [19] summarized the 
correct shape factor formulas considering constant drainage rate from a matrix block and constant pressure in the adjacent fractures through numerical simulation. However, the above research mainly analyzed the gas drainage effect in conventional borehole gas drainage. There are few studies on gas drainage with long boreholes along the seam.

On the other hand, to evaluate the effect of long borehole gas drainage, it is necessary to study the reasonable length of the borehole for long borehole drainage [20-22]. If the length of the borehole is too large, due to the attenuation of the negative pressure in the borehole, the gas content at the bottom of the long borehole will be high, making it difficult to reach the drainage index. If the length of the borehole is too short, it will result in low efficiency of gas drainage measures [23-25]. At present, the methods to determine the effective gas drainage radius include on-site measurement and theoretical calculation methods [26, 27]. The on-site measurement mainly determines the residual gas content of the gas after the gas drainage. In terms of theoretical calculations, the effective gas drainage radius is determined mainly based on the gas flow theory in the borehole and the characteristics of coal seam gas seepage. $[28,29]$ The practice of predecessors in gas drainage has achieved remarkable results. In the case of a short borehole length, the negative pressure of gas drainage in the borehole does not decrease significantly, and there is still a large negative pressure for gas drainage at the bottom of the borehole. After a period of time of extraction, there is little difference in residual gas content before and after the borehole. However, for long boreholes along the bedding, when the negative pressure attenuation is apparent, the residual gas content at the bottom of the borehole is still relatively large. Therefore, it is necessary to study the reasonable length of the borehole for long borehole drainage.

This paper first elaborates and establishes a multifield coupling model of gas migration in coal which considers coal matrix gas diffusion, fissure gas seepage, permeability evolution law, and coal deformation law. Then, the change value of the residual gas content per unit time is used to calculate the gas drainage volume and then quantify the gas drainage effect of the long borehole. Finally, the COMSOL software was adopted, and the fully coupled numerical simulation method was used to analyze the drainage effects of different layouts and lengths of long boreholes along the bedding. The research results are expected to provide a theoretical basis for gas drainage from long boreholes along the bedding.

\section{Multifield Coupling Model for Gas-Bearing Coal Seams}

2.1. Model Assumptions. The multifield coupling model for gas-bearing coal seams is established based on the following assumptions:

(a) Coal seam is a homogeneous, isotropic, doubleporosity elastic medium

(b) The influence of water on gas migration in coal seams is ignored

(c) The coal seam is an isothermal system, and gas is an ideal gas (d) The strain of the coal skeleton is infinitesimal [14, $16,17]$

2.2. Effective Stress Principle. In order to better describe the mechanical response of pore and fissure dual media under gas pressure, the effective stress law of dual porous media is introduced when establishing the permeability model [16]:

$$
\sigma_{\mathrm{ij}}^{e}=\sigma_{\mathrm{ij}}-\left(\beta_{f} p_{f}+\beta_{m} p_{m}\right) \delta_{\mathrm{ij}}
$$

where $\sigma_{\mathrm{ij}}^{e}$ is the effective stress, $\mathrm{MPa} ; \sigma_{\mathrm{ij}}$ is the total stress, $\mathrm{MPa} ; \delta_{\mathrm{ij}}$ is the Kronecker delta (1 for $i=j$ and 0 for $\left.i \neq j\right) ; p_{f}$ and $p_{m}$ are pressure in the fractures and matrix blocks, respectively, $\mathrm{Pa}$; and $\beta_{f}$ and $\beta_{m}$ are the effective stress coefficients for pore and fracture, respectively.

The effective stress coefficients $\beta_{f}$ and $\beta_{m}$ of the cracks in (1) can be calculated by the following formulas, respectively:

$$
\begin{aligned}
& \beta_{f}=1-\frac{K}{K_{m}}, \\
& \beta_{m}=\frac{K}{K_{m}}-\frac{K}{K_{s}},
\end{aligned}
$$

where $K$ is the bulk modulus of the coal body, $\mathrm{MPa} ; K_{m}$ is the bulk modulus of the coal matrix, $\mathrm{MPa}$; and $K_{s}$ is the bulk modulus of the coal body skeleton, $\mathrm{MPa}$.

The following formulas can calculate the above three bulk moduli:

$$
\begin{aligned}
K & =\frac{E}{3(1-2 v)}, \\
K_{m} & =\frac{E_{m}}{3(1-2 v)}, \\
K_{s} & =\frac{K_{m}}{1-3 \phi_{m}(1-v) /[2(1-2 v)]},
\end{aligned}
$$

where $E$ is the elastic modulus of the coal body, $\mathrm{MPa} ; E_{m}$ is the elastic modulus of the coal matrix, MPa; $v$ is Poisson's ratio of the coal; and $\phi_{m}$ is the coal matrix porosity, $\%$.

2.3. Dynamic Evolution Equation of Coal Porosity and Permeability. Palmer and Mansoori [30] proposed a widely used permeability model (PM model) suitable for uniaxial strain conditions. However, the PM model was established based on the coal seam containing only cracks. The coal seam is usually modeled as a dual-porosity medium containing both cracks and pores. Therefore, this study adopts the dual-porosity poroelasticity theory. The revised crack porosity model is shown in the following equation:

$$
\begin{aligned}
\frac{\phi_{f}}{\phi_{f 0}}= & \frac{\varepsilon_{L}}{\phi_{f 0}}\left(\frac{K}{M}-1\right)\left(\frac{p_{m}}{P_{L}+p_{m}}-\frac{p_{0}}{P_{L}+p_{0}}\right)+1 \\
& +\frac{1}{M \phi_{f 0}}\left(\beta_{f}\left(p_{f}-p_{0}\right)+\beta_{m}\left(p_{m}-p_{0}\right)\right),
\end{aligned}
$$


where $\phi_{f}$ is the fracture porosity, $\%$; $\phi_{f 0}$ is the initial fracture porosity, $\% ; \varepsilon_{L}$ is Langmuir volumetric strain constant; $P_{L}$ is Langmuir pressure constant; $M$ is the limiting axial modulus, $\mathrm{MPa}$; and $p_{0}$ is the initial pressure in the matrix blocks, Pa.

According to the Kozeny-Carman equation [31, 32], the coal seam permeability $k$ is

$$
\frac{k}{k_{0}}=\left(1+\frac{1}{M \phi_{f 0}}\left(\beta_{f}\left(p_{f}-p_{0}\right)+\beta_{m}\left(p_{m}-p_{0}\right)\right)+\frac{\varepsilon_{L}}{\phi_{f 0}}\left(\frac{K}{M}-1\right)\left(\frac{p_{m}}{P_{L}+p_{m}}-\frac{p_{0}}{P_{L}+p_{0}}\right)\right)^{3}
$$

where $k_{0}$ is the coal seam permeability, $\mathrm{m}^{2}$.

2.4. Diffusion Equation of Gas in Coal. The mass exchange between the matrix and the fissures in the coal body can be expressed by the following equation:

$$
Q_{m}=D \chi \frac{M_{C}}{\mathrm{RT}}\left(p_{\mathrm{m}}-p_{f}\right)
$$

where $Q_{m}$ is the mass exchange between coal pores and cracks, $\mathrm{kg} /\left(\mathrm{m}^{3} \cdot \mathrm{s}\right) ; \chi$ is the matrix shape factor, $\mathrm{m}^{-2} ; M_{C}$ is the molar mass of methane, $\mathrm{kg} / \mathrm{mol} ; D$ is gas diffusion coefficient, $\mathrm{m}^{2} / \mathrm{s} ; R$ is the universal gas constant, $\mathrm{J} /(\mathrm{mol} \cdot \mathrm{K})$; and $T$ is the coal seam temperature, $\mathrm{K}$.

The following formula can calculate the diffusion coefficient:

$$
D=D_{0} \exp (-\xi t)
$$

where $\xi$ is the attenuation coefficient of the dynamic diffusion coefficient, $\mathrm{s}^{-1}$, and $\mathrm{D}_{0}$ is the initial gas diffusion coefficient, $\mathrm{m}^{2} / \mathrm{s}$.

According to the Langmuir equation, the gas content per unit volume of coal matrix can be obtained as

$$
m_{p}=\frac{a b p_{m} \rho_{c} M_{C}}{\left(1+b p_{m}\right) V_{m}}+\phi_{m} \frac{M_{C} p_{m}}{\mathrm{RT}}
$$

where $m_{p}$ is the gas content per unit mass of the coal matrix, $\mathrm{kg} / \mathrm{m}^{3} ; \rho_{c}$ is the apparent density of the coal, $\mathrm{kg} / \mathrm{m}^{3} ; \phi_{m}$ is the matrix porosity, \%; $a$ is the Langmuir volume constant, $\mathrm{m}^{3}$ / $\mathrm{kg} ; b$ is the reciprocal of Langmuir pressure constant, $\mathrm{Pa}^{-1}$; and $V_{m}$ is the molar volume of methane under standard conditions, $\mathrm{m}^{3} / \mathrm{mol}$.

From the conservation of mass, it can be seen that the relationship between the amount of change in matrix gas content and $Q_{m}$ is

$$
\frac{\partial m_{p}}{\partial t}=-Q_{m}
$$

Substituting (6) (8) into (9), the governing equation for gas diffusion is

$$
\frac{\partial p_{m}}{\partial t}=-\frac{b \chi V_{m}\left(p_{m}-p_{f}\right)\left(p_{m}+P_{L}\right)^{2}}{a R T \rho_{c}+b \phi_{m} V_{m}\left(p_{m}+P_{L}\right)^{2}} D_{0} \exp (-\xi t)
$$

2.5. The Seepage Equation of Gas in Coal. According to the law of conservation of mass, the change in gas mass in a fracture is equal to the gas diffused into the fracture by the pore minus the gas flowing into the borehole from the fracture; namely,

$$
\frac{M_{C}}{\mathrm{RT}} \frac{\partial \phi_{f} p_{f}}{\partial t}=Q_{m}\left(1-\phi_{f}\right)-\nabla\left(\frac{M_{C}}{\mathrm{RT}} p_{f} \nu_{f}\right),
$$

where $v_{f}$ is the gas flow velocity in the crack, $\mathrm{m} / \mathrm{s}$.

Moreover, the flow of gas in the cracks of the coal body conforms to Darcy's law; then,

$$
v_{f}=-\frac{k}{\mu} \nabla p_{f}
$$

where $\mu$ is the dynamic viscosity of the gas, Pa.s.

By combining the above equations, the governing equation of gas percolation can be obtained as

$$
\phi_{f} \frac{\partial p_{f}}{\partial t}+p_{f} \frac{\partial \phi_{f}}{\partial t}-\nabla\left(p_{f} \frac{k}{\mu} \nabla p_{f}\right)=D \chi\left(p_{m}-p_{f}\right)\left(1-\phi_{f}\right) \text {. }
$$

2.6. Deformation Equation of Gas-Bearing Coal. The deformation equation of gas-containing coal is composed of the stress balance equation, geometric deformation equation, and stress-strain relationship [33], which can be expressed as

$$
G u_{i, j j}+\frac{G}{1-2 v} u_{j, j i}-\beta_{f} p_{f, i}-\beta_{m} p_{m, i}+F_{i}=0
$$

where $G$ is the coal's shear modulus, MPa, and $u_{i}$ is the displacement component in the $i$-direction.

The above control equations constitute a multifield coupling model for gas-containing coal seams that comprehensively consider the coal skeleton compression effect (effective stress effect) and matrix shrinkage effect. The coupling relationship between the physical fields is shown in Figure 1 .

\section{Geometric Model and Definite Solution Conditions}

3.1. Geometric Model. In order to analyze the effect of gas drainage with long boreholes along the seam, two gas 


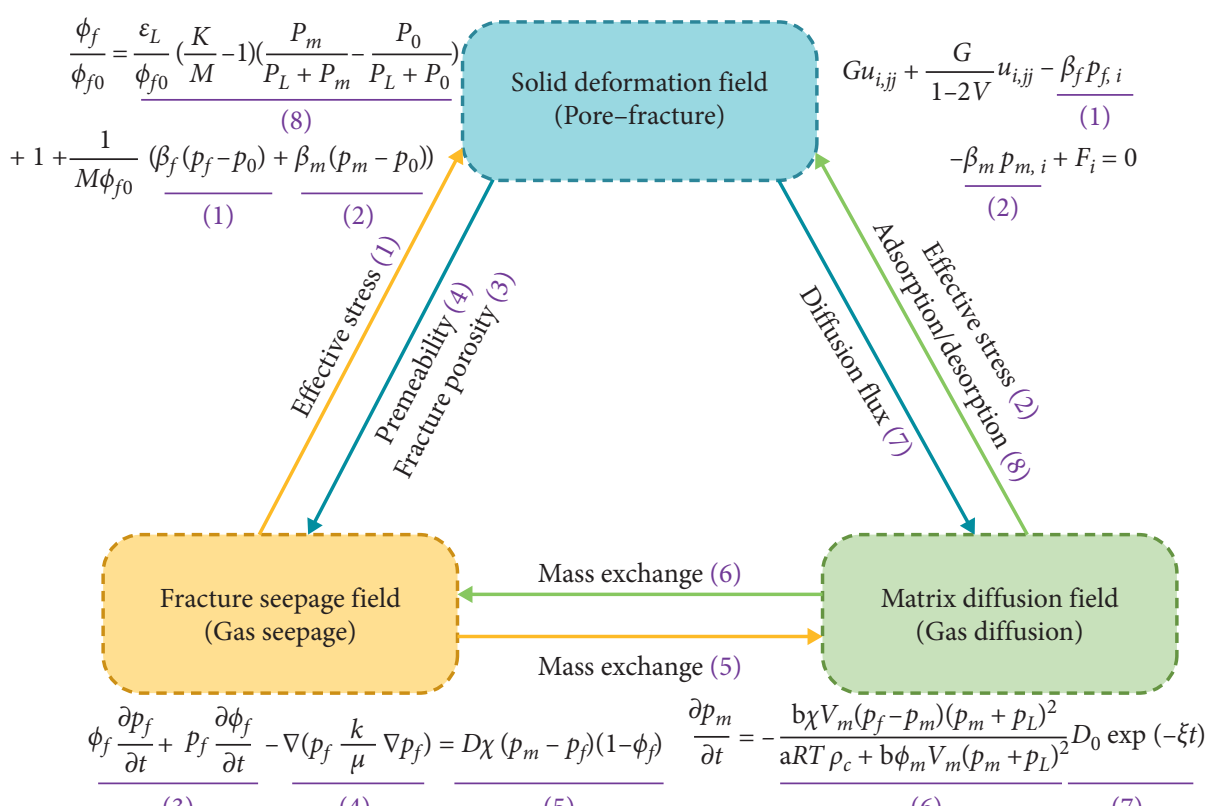

(3)

(4)

(5)

(6)

(7)

FIGURE 1: Schematic diagram of physics coupling relationship.

drainage schemes under two conditions have been established :

(1) Gas drainage with long boreholes along the seam The geometric model is shown in Figure 2. The $240 \mathrm{~m}$ long boreholes along the seam were constructed in the direction of the coal seam's inclination in the machine roadway or wind roadway in the working face. The borehole spacing distance is $2 \mathrm{~m}$, and ten long boreholes along the seam were constructed.

(2) The combination of long boreholes along the seam and penetrating boreholes

The geometric model is shown in Figure 3. The $90 \mathrm{~m}$ long boreholes along the seam were constructed in the machine lane and the winding lane in the working face along the direction of the inclination of the coal seam. The borehole spacing distance is $2 \mathrm{~m}$, and 20 long boreholes along the seam were constructed. Moreover, the penetrating boreholes were constructed in the middle of the working face of the bottom-drawing roadway, and the position of the final hole of the penetrating boreholes is shown in Figure 3. The boreholes are spaced $2 \mathrm{~m}$ apart in both the strike and inclination directions, and a total of 290 penetrating boreholes have been constructed.

The size of the coal seam under these two drainage schemes is $400 \times 240 \mathrm{~m}$.

The numerical simulation software used in this study is COMSOL Multiphysics. The simulation uses the PDE module and the solid mechanics module in COMSOL to calculate the model. The parameters used in the numerical simulation are shown in Table 1 [17].
3.2. Model Validation. To verify the correctness of the multi-field coupling model of gas-bearing coal seams established in this paper, the use of mathematical models of Liu et al. [16] coal seam gas pressure data was compared to verify. A model consisting of three horizontal coal layers was established. There is a coal seam with a width of 40 meters and a height of 4 meters between the two rock layers. The drill hole is located in the center of the coal seam. The other parameters used in the model are consistent with those in the Liu model. After COMSOL numerical calculation, the experimental results are shown in Figure 4. It can be seen from Figure 4 that the gas-solid coupling model established in this paper is in good agreement with Liu's model.

\section{Quantitative Characterization of Gas Drainage Effect in Boreholes}

It can be seen from Section 1 that, at time $t$ and $t+\Delta t$, the gas content in the coal seam is

$$
\begin{aligned}
m_{t} & =\frac{V_{L} p_{m}(t)}{p_{m}(t)+P_{L}} \frac{M_{c}}{V_{M}} \rho_{c}+\phi_{m} \frac{M_{c}}{R T} p_{m}(t), \\
m_{t+\Delta t} & =\frac{V_{L} p_{m}(t+\Delta t)}{p_{m}(t+\Delta t)+P_{L}} \frac{M_{c}}{V_{M}} \rho_{c}+\phi_{m} \frac{M_{c}}{R T} p_{m}(t+\Delta t) .
\end{aligned}
$$

In the formula, $m_{t}$ and $m_{t}+\Delta m_{t}$ represent the gas content in the coal seam when the drainage time is $t$ and $t+\Delta t$, respectively.

According to the above formula, the gas content extracted from the coal seam after the gas drainage of $\Delta t$ time is as follows: 


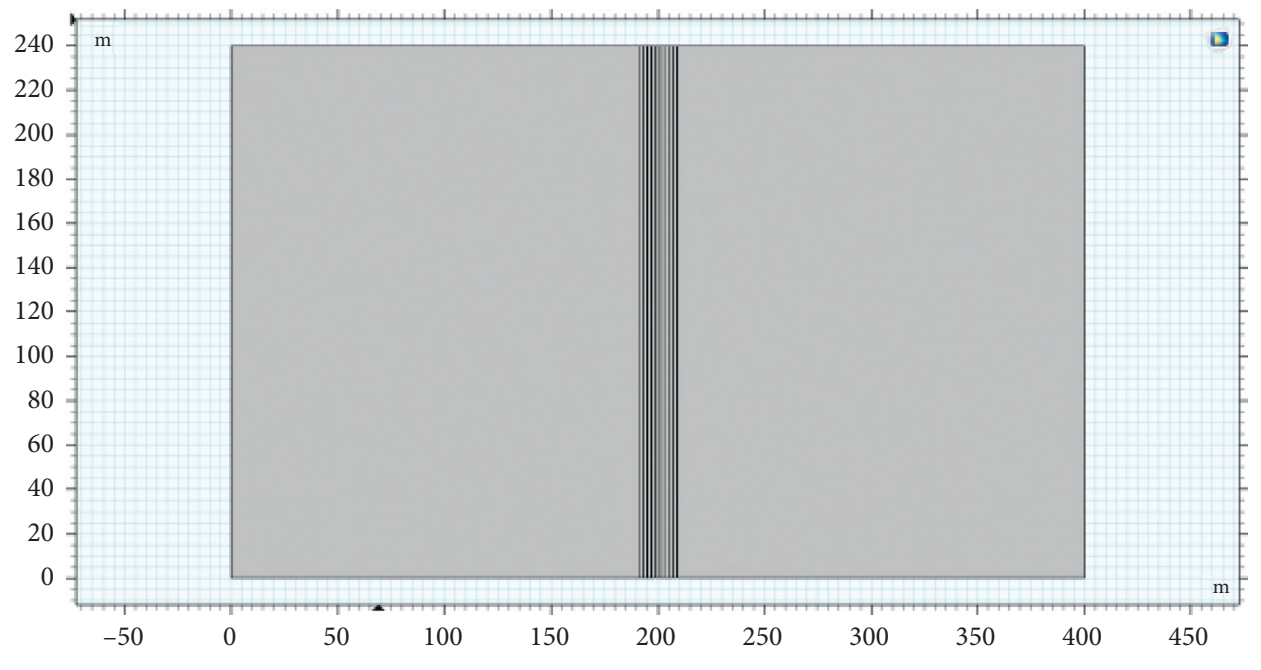

FIgURE 2: The arrangement of long boreholes along the seam.

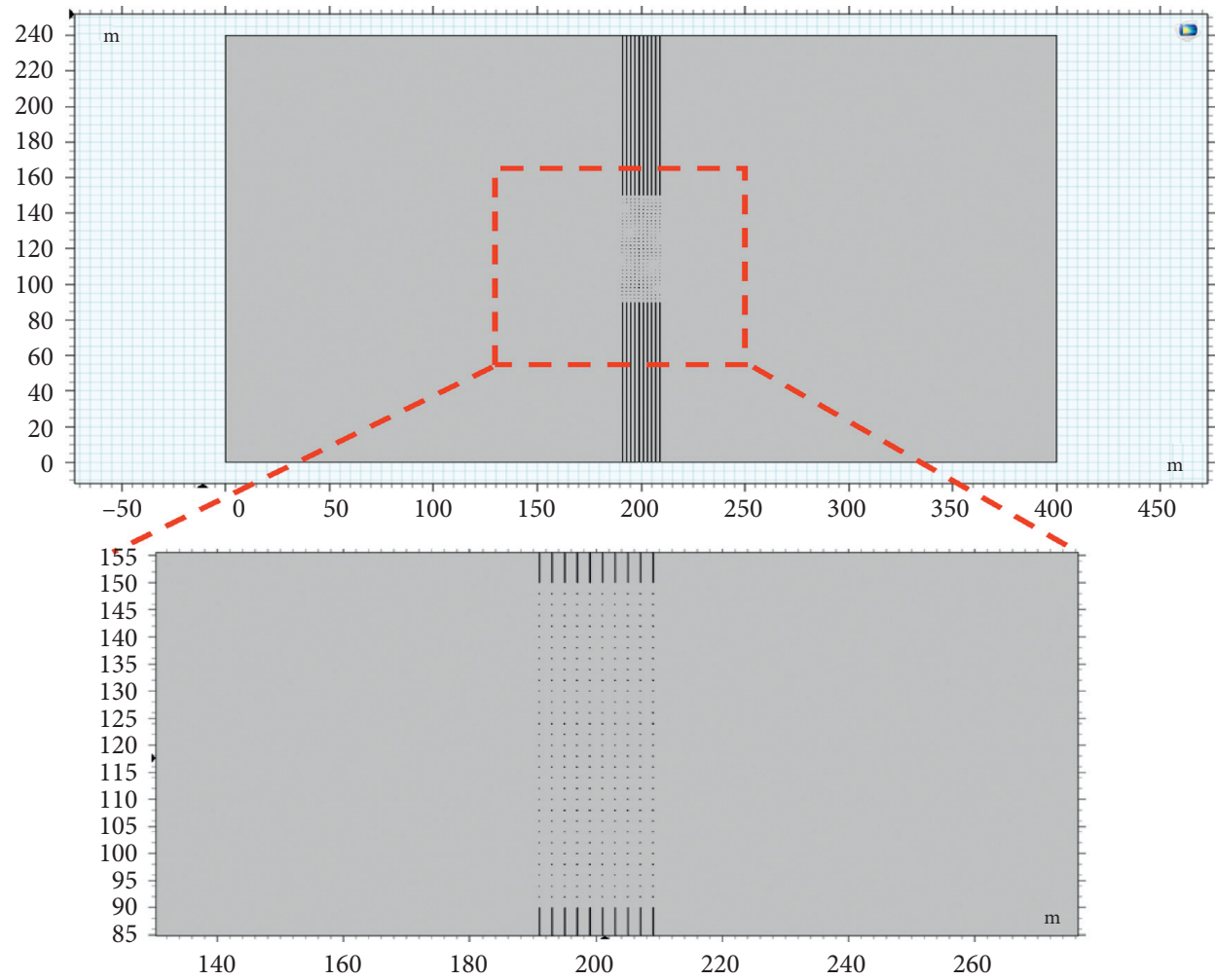

Figure 3: Borehole layout method for gas drainage combined with long boreholes along the seam and penetrating boreholes.

$$
m_{\triangle t}=\iint_{\Omega}\left(m_{t}-m_{t+\Delta t}\right) \mathrm{d} v
$$

Based on the above formula, the gas content extracted within a certain period can be obtained by integration with COMSOL software.

\section{Results and Discussion}

5.1. Influence of Drilling Layout on the Effect of Gas Drainage. Figure 5 is a cloud map of coal seam gas content under different drainage times in long boreholes along the seam. It can be seen from Figure 5 that, under the action of negative 
TABLe 1: Parameters used in numerical simulation [17].

\begin{tabular}{lc}
\hline Parameter & Value \\
\hline Modulus of elasticity of coal & $2713 \mathrm{MPa}$ \\
Poisson's ratio of coal & 0.339 \\
Initial porosity & 0.072 \\
Initial gas pressure & $1.08 \mathrm{MPa}$ \\
Initial coal permeability & $0.02 \mathrm{mD}$ \\
Coal initial diffusion coefficient & $1 \times 10^{-12} \mathrm{~m}^{2} / \mathrm{s}$ \\
Attenuation coefficient & $2 \times 10^{-8} \mathrm{~s}^{-1}$ \\
Langmuir pressure constant & $1.8672 \mathrm{MPa}^{-1}$ \\
Langmuir volume constant & $14.4348 \mathrm{~m}^{3} / \mathrm{t}$ \\
Coal density & $1250 \mathrm{~kg} / \mathrm{m}^{3}$ \\
The molar mass of methane & $0.016 \mathrm{~kg} / \mathrm{mol}^{3}$ \\
Drainage time & $360 \mathrm{~d}$ \\
Time step & $1 \mathrm{~d}$ \\
Ambient temperature & $293 \mathrm{~K}$ \\
\hline
\end{tabular}

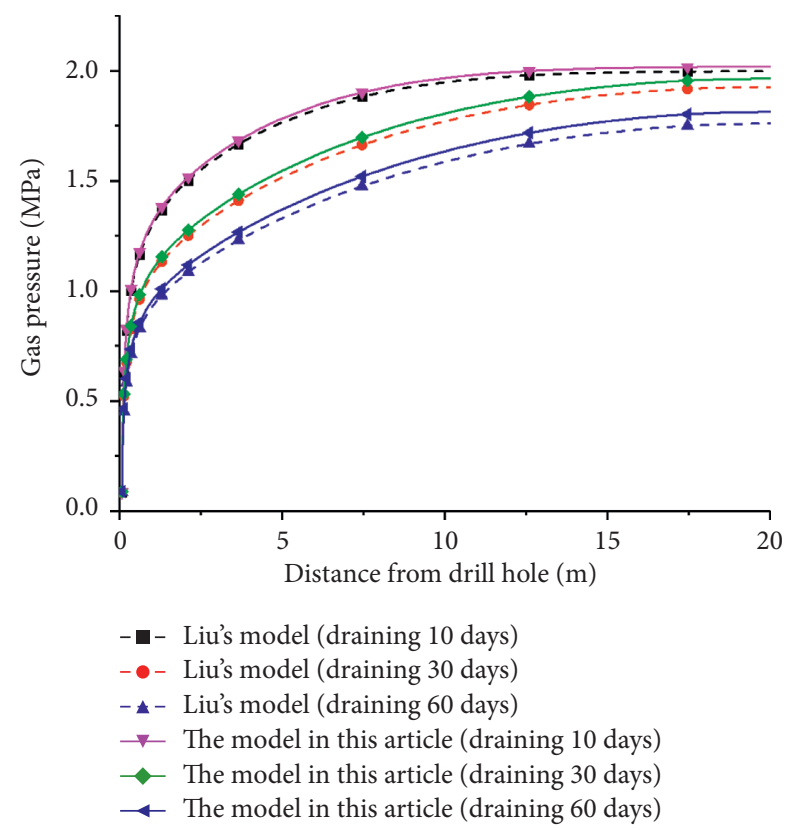

FIgURE 4: Data comparison between the model in this article and Liu's model at different extraction times.

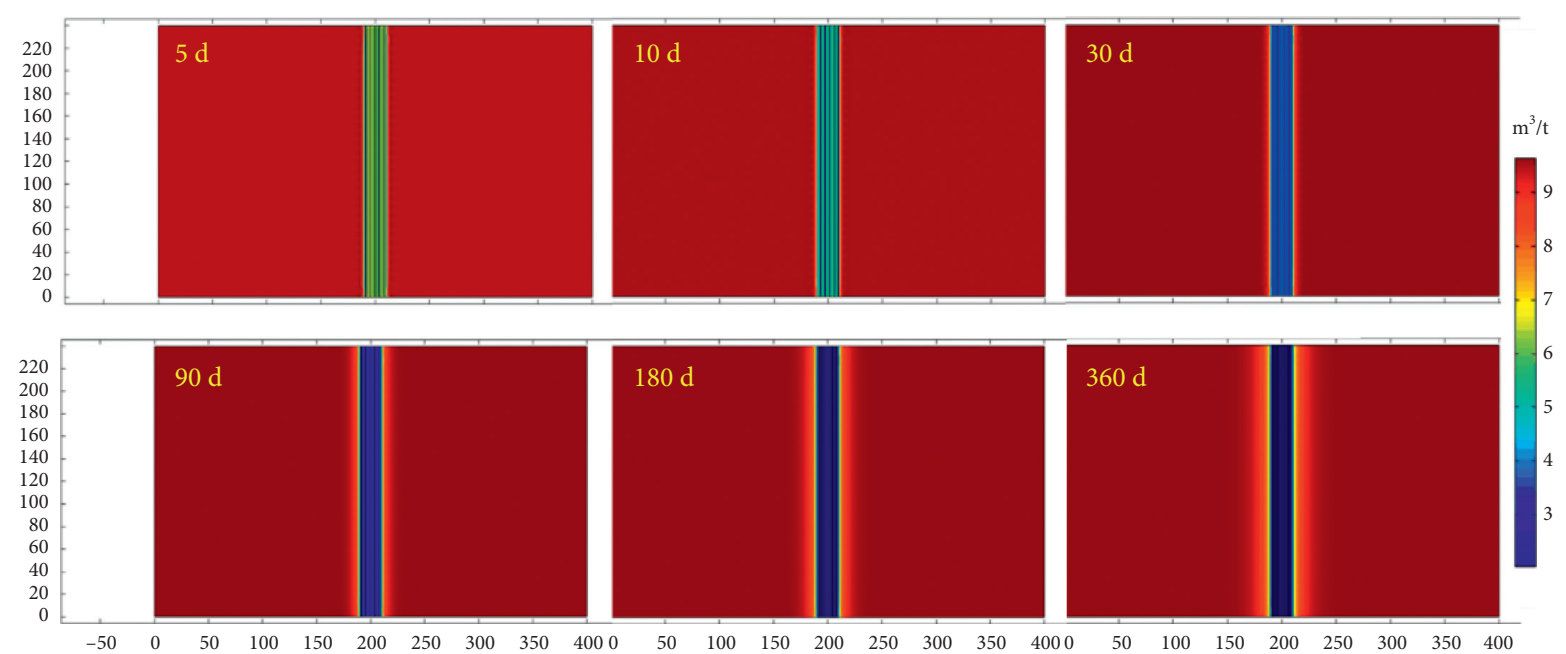

Figure 5: Cloud map of coal seam gas content under different drainage time in the case of long boreholes along the seam. 


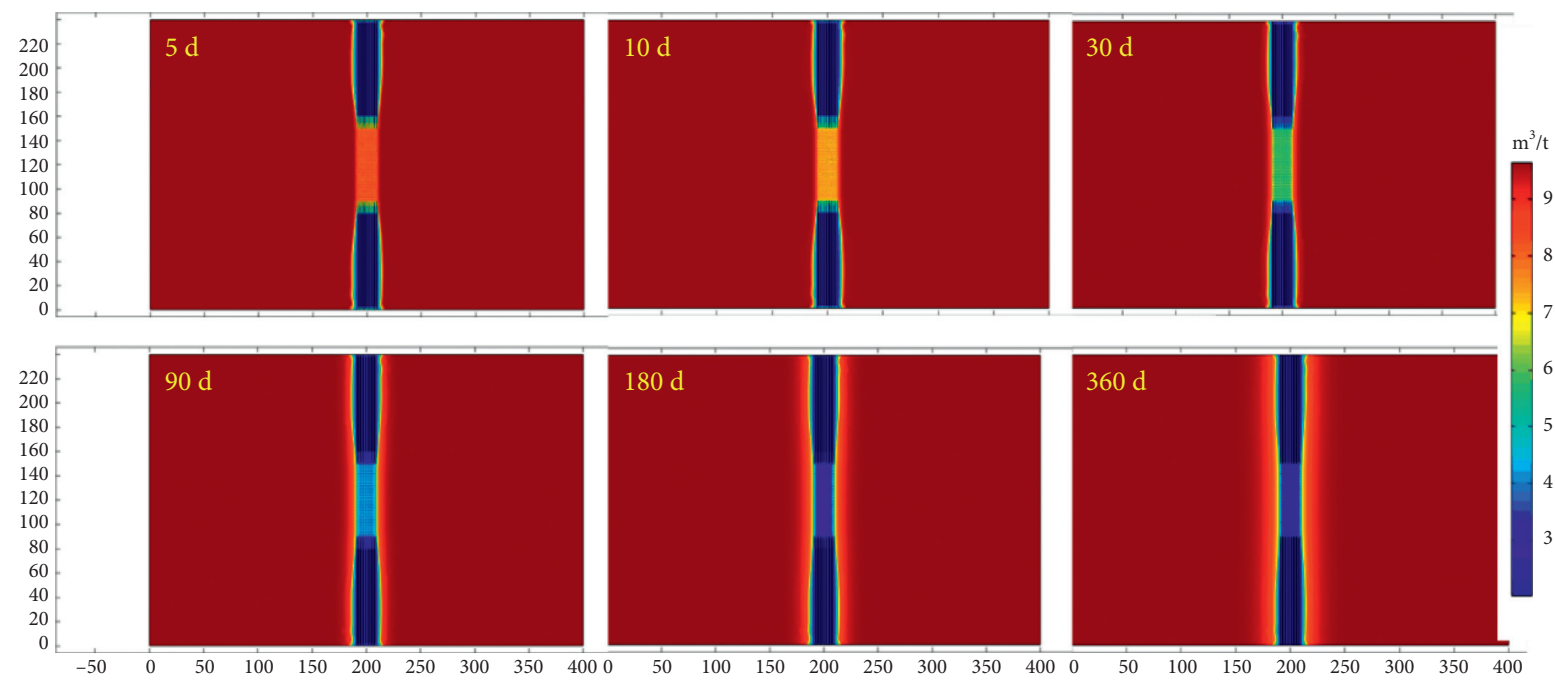

FIGURE 6: Cloud map of coal seam gas content under different drainage times under the combined drainage of long boreholes along the seam and penetrating boreholes.

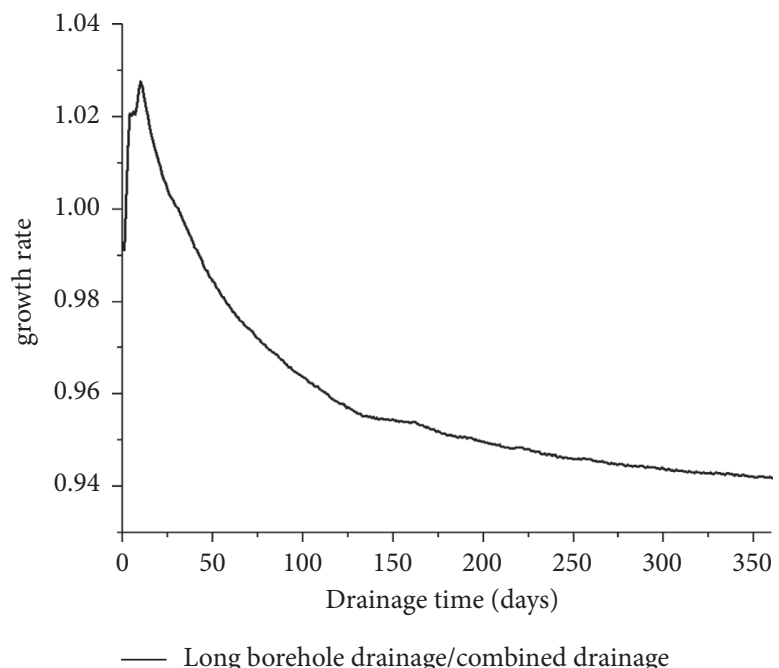

FIgURE 7: Long boreholes drainage growth rate.

pressure in the borehole, the gas pressure around the borehole is significantly lower than that of the distant coal body. Furthermore, because the borehole spacing distance is only $2 \mathrm{~m}$, the gas pressure between the drill holes is significantly reduced, and there is no apparent blank zone. In addition, the length of the borehole reaches 240 meters and runs through the entire working face. Therefore, the contact area between the borehole and the coal body is large, and the drainage effect is good. On the other hand, as the drainage time increases, the gas content around the borehole gradually decreases, and the influence range of borehole drainage gradually increases. For example, after 360 days of drainage, the gas content of the coal body covered by the borehole was significantly reduced to $3 \mathrm{~m}^{3} / \mathrm{t}$, which was significantly lower than the gas content of 5 days of drainage.

At present, due to limited drilling rig equipment in some domestic mining areas, the construction length of long boreholes along the seam is limited, so there must be a blank zone of gas drainage in the middle of the working face. To ensure the safety of the working face during the mining period, penetrating boreholes are usually used to extract the coal seam gas in the middle of the working face. The boreholes arrangement in this section is based on the above facts.

Figure 6 is a cloud map of coal seam gas content under different drainage times in combined drainage with long boreholes along the seam and penetrating boreholes. It can be seen from Figure 6 that the distribution of residual gas content in coal seams is different from that in Figure 5. The gas content in long boreholes along the seam drainage area is significantly lower than that of penetrating boreholes drainage area. For example, at five days of drainage, the gas content in the area covered by the long boreholes along the seam has dropped to $4 \mathrm{~m}^{3} / \mathrm{t}$, while the gas content in the penetrating boreholes covering the coal seam is about $8 \mathrm{~m}^{3} / \mathrm{t}$. According to the analysis in Section 1, the gas drainage 


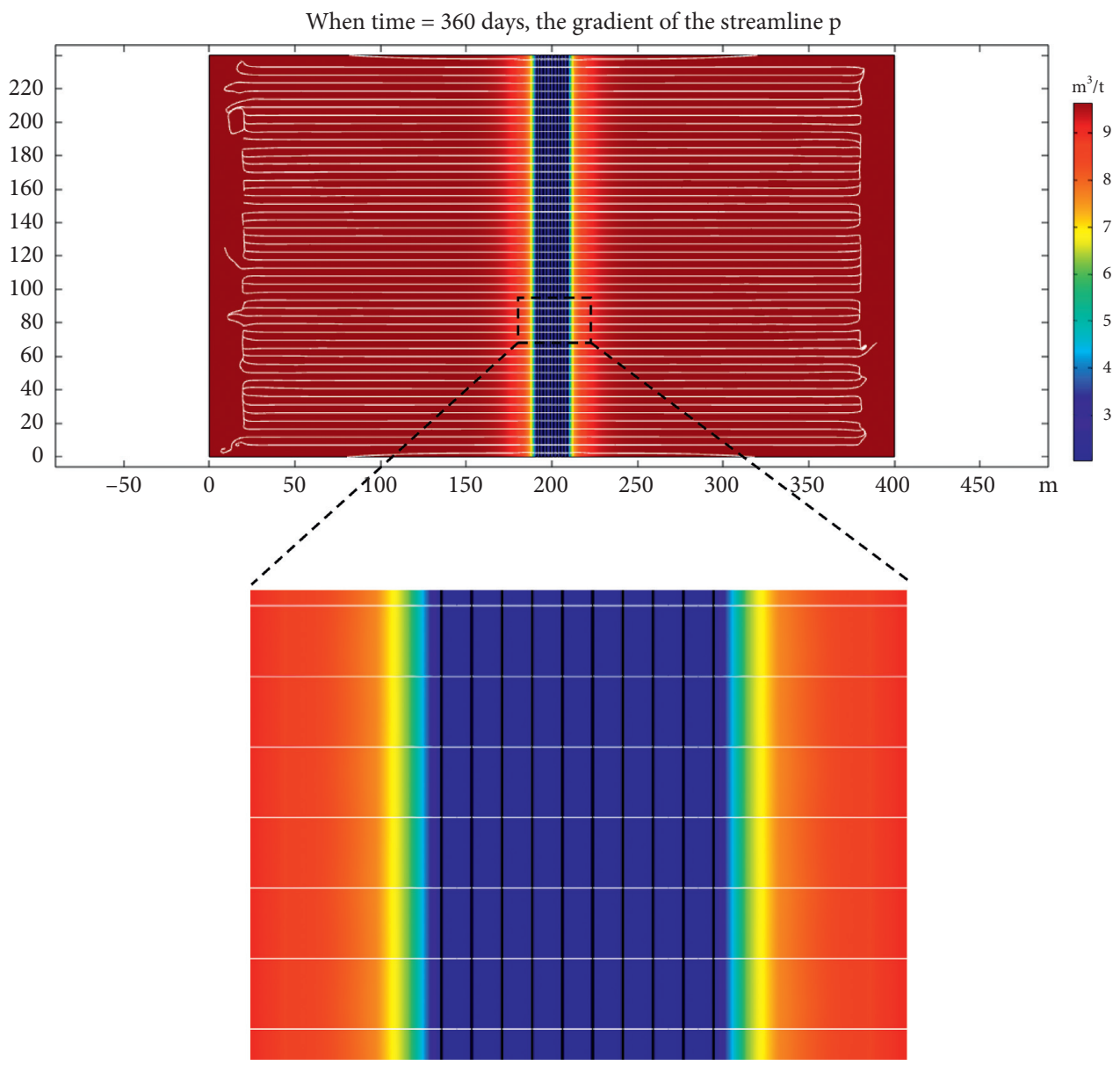

Figure 8: Streamline diagram of the long boreholes along the seam.

volume per unit time of a borehole is mainly determined by the permeability and the contact area of the borehole. Therefore, the gas drainage effect of long boreholes along the seam is significantly higher than that of penetrating boreholes. In addition, with the increase of the extraction time, the gas content of the coal body around the borehole is consistent with the previous analysis. One point that needs to be particularly pointed out is that, with the increase of the drainage time, the difference between the gas drainage effect of the long boreholes along the seam and the penetrating boreholes gradually decreases.

For example, at 360 days of drainage, the gas content in the long boreholes along the seam area is about $2.5 \mathrm{~m}^{3} / \mathrm{t}$, and the gas content in the penetrating boreholes area is also reduced to about $3 \mathrm{~m}^{3} / \mathrm{t}$.

It can be seen that the drainage effect of the long boreholes along the seam arrangement is significantly higher than that of the combined long boreholes along the seam and penetrating boreholes. However, it is difficult to intuitively compare the drainage effects of the two drilling arrangements based on the distribution cloud map of the residual gas content after coal seam drainage. To solve the problems mentioned above, this paper proposes a quantitative characterization method for the effect of borehole gas drainage in Section 3. Based on this quantitative characterization method, the gas drainage volume under different borehole layouts can be obtained. This paper takes the combined drainage volume of long boreholes along the seam and penetrating boreholes as the benchmark. It can be concluded that there is an increase in drainage under the condition of long boreholes along the seam relative to the combined drainage, as shown in Figure 7. It can be seen from Figure 7 that the gas drainage volume in the bedding long borehole layout is similar to the gas drainage volume under the combined layout under the same drainage time. For example, in the early stage of drainage, the drainage volume under the long borehole layout is 1.025 times that of the combined drainage, and it gradually decreases in the later stage, down to 0.94 times at the lowest level. In addition, considering the construction cost of tunnel extraction and drilling through layers, it can be considered that the long boreholes along the seam can reduce the pressure and content of coal seam gas faster in the process of gas drainage in coal mines. The danger of gas outbursts in the working face is eliminated, and construction costs are reduced.

Figures 8 and 9 are the streamline diagram of the long boreholes along the seam and the streamline diagram of the combined boreholes through bedding during the 360-day drainage. It can be seen from Figure 8 that the gas migration streamlines of the long boreholes along the seam are 


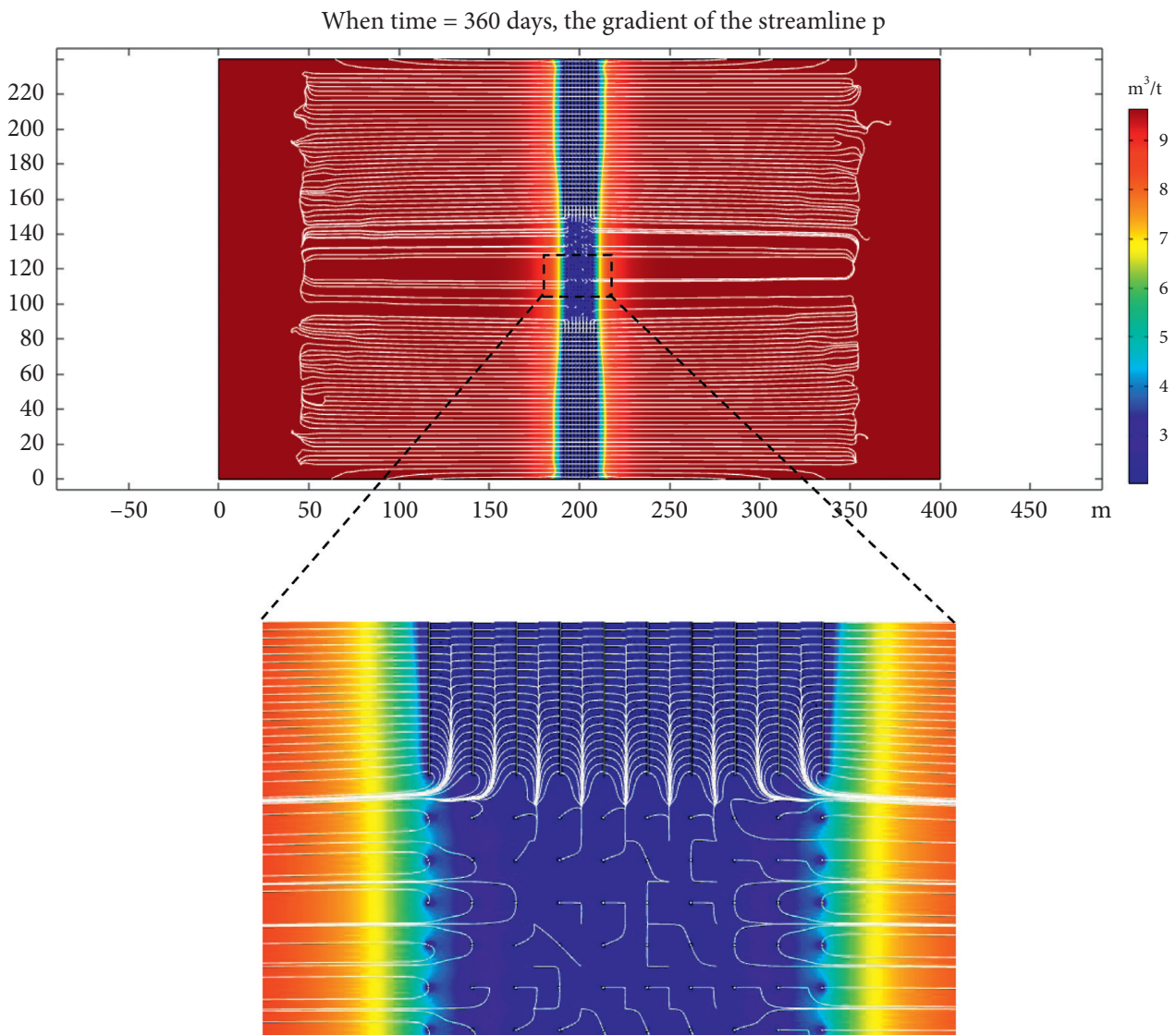

Figure 9: Streamline diagram of the combined layout of penetrating boreholes and the long boreholes along the seam.

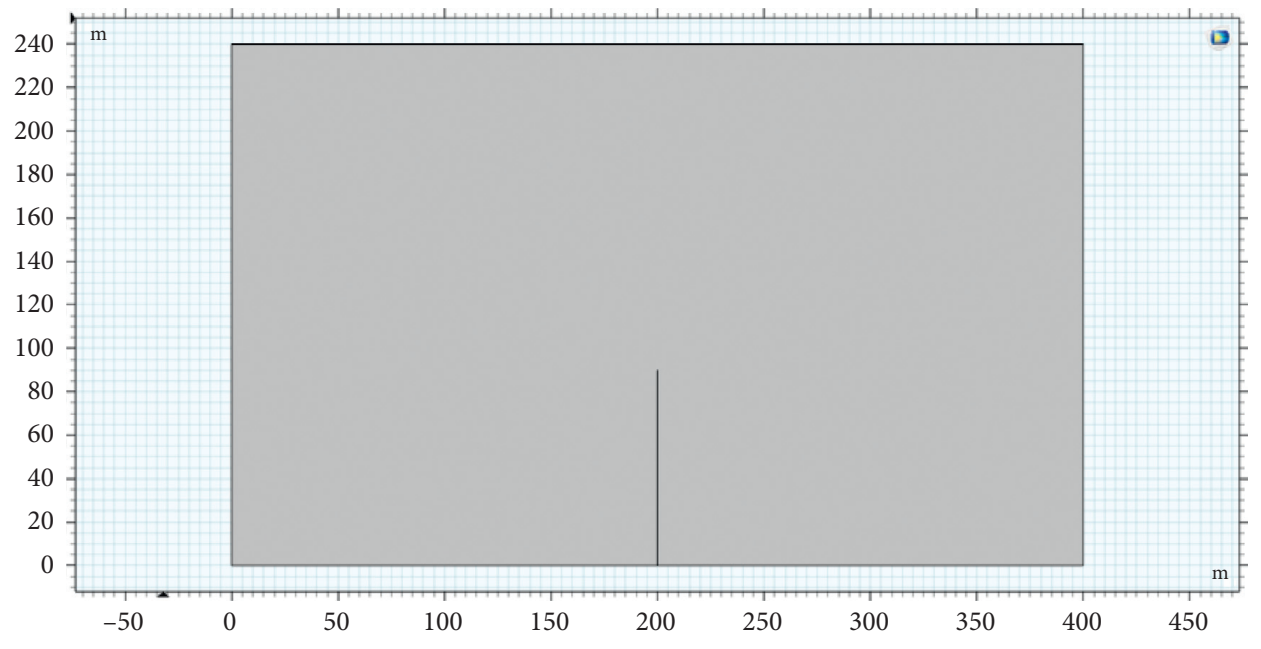

FIGURE 10: $90 \mathrm{~m}$ drilling geometry model.

perpendicular to the borehole. The gas flows neatly and orderly to the boreholes, with almost no influence on each other, conforming to radial flow. It can be seen from Figure 9 that the gas streamlines in the long boreholes along the seam area still show a radial flow, while the gas flow in the penetrating boreholes area is messy. In addition, the turbulent gas streamlines interfere with each other at the intersection of the long boreholes along the seam and penetrating boreholes. The gas migration between boreholes is subject to drainage forces in multiple directions, not conducive to gas drainage.

The above analysis compares and analyzes the drainage effect of the arrangement of long boreholes along the seam and the combined arrangement of penetrating boreholes and the long boreholes along the seam from the three aspects of gas drainage volume, gas flow line, and drilling construction 


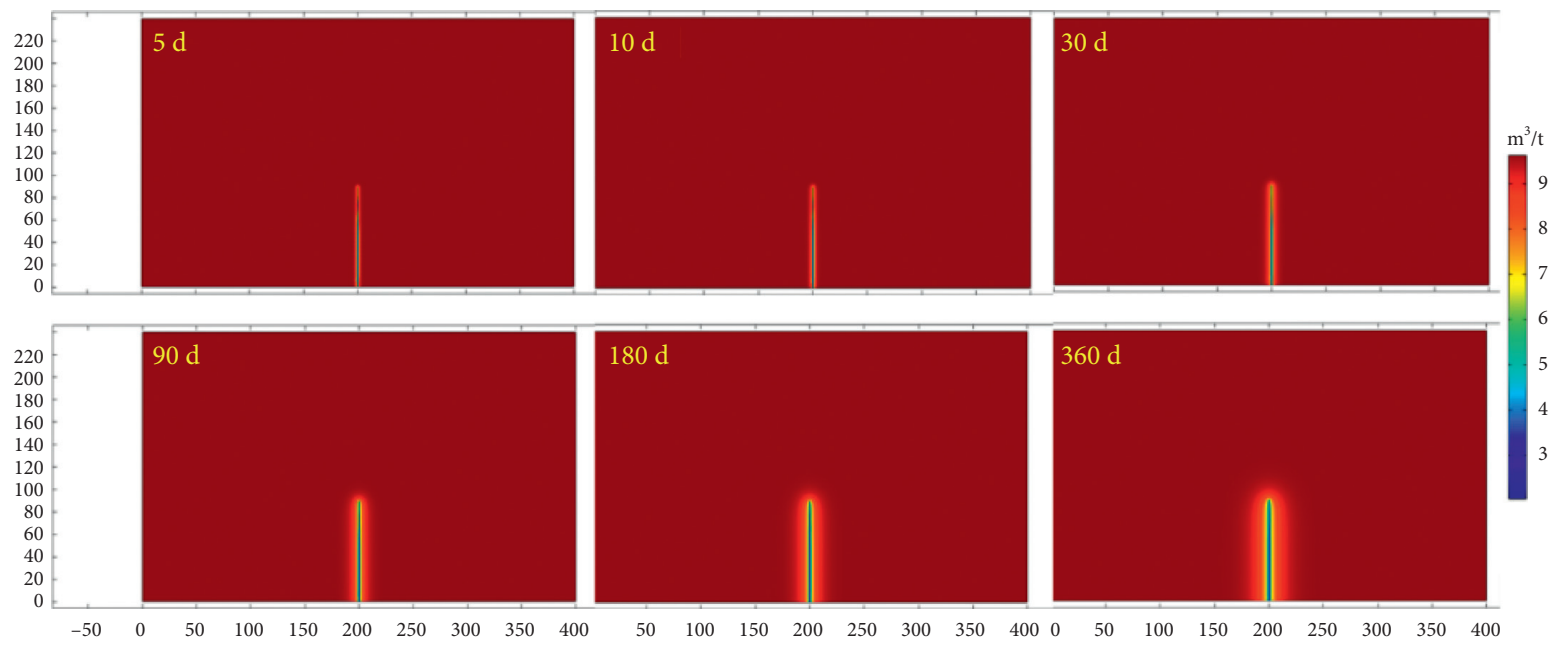

FIgURE 11: Cloud map of coal seam gas content distribution under different drainage time of 90-meter borehole.

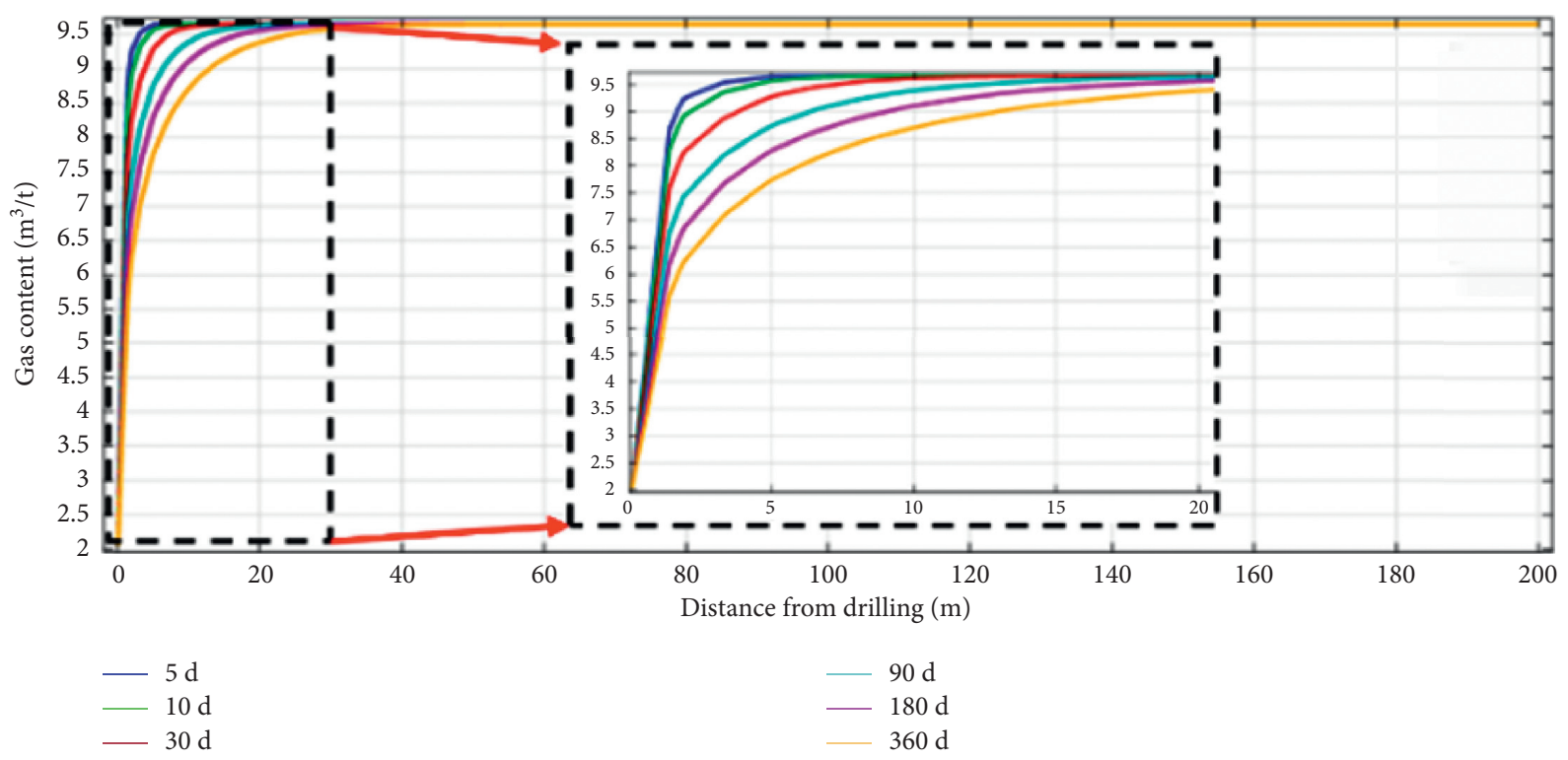

(a)

FIgURE 12: Continued. 


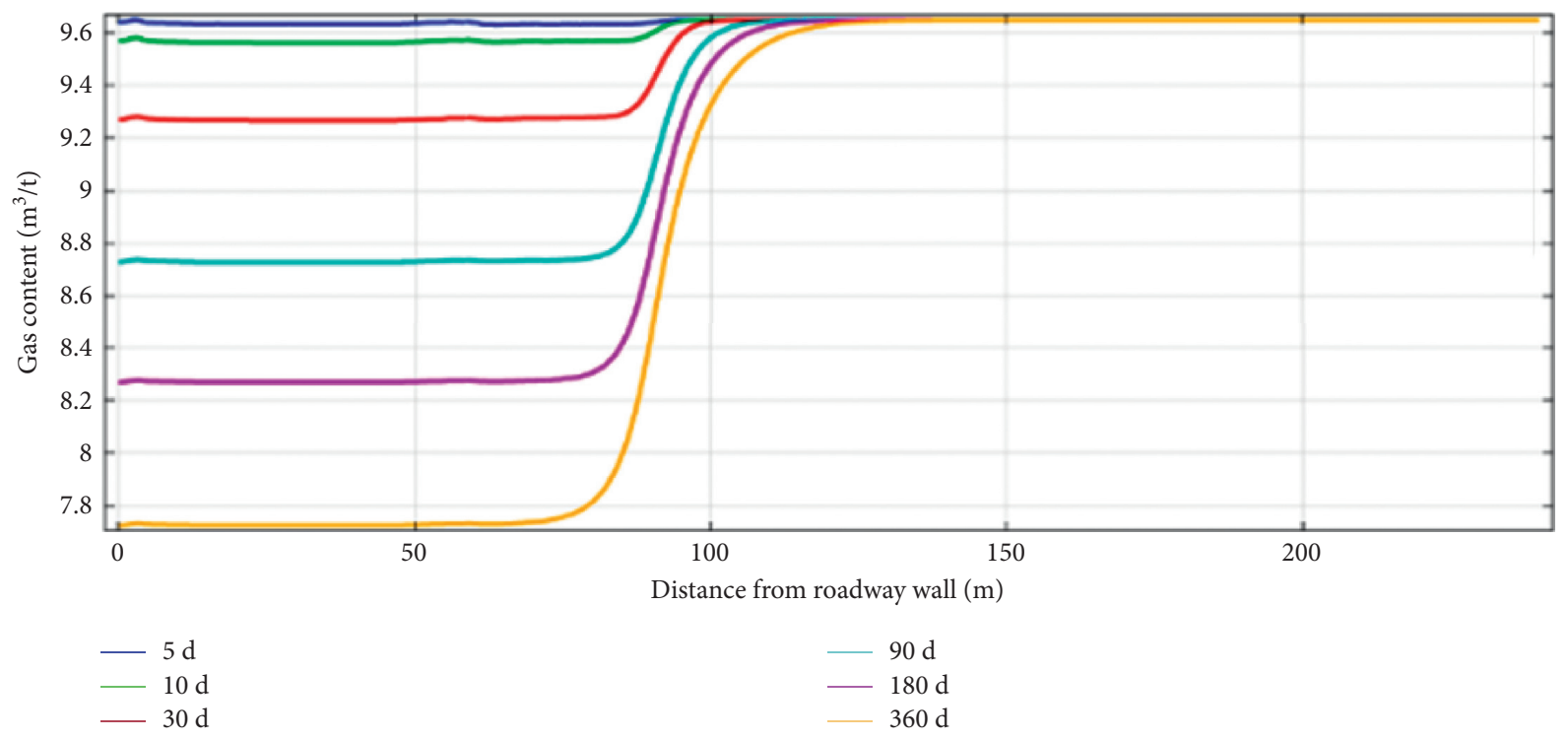

(b)

Figure 12: Distribution of gas content in $90 \mathrm{~m}$ borehole with different drainage time: (a) gas content distribution on the monitoring line in the strike direction; (b) distribution of gas content in the trend direction monitoring line.

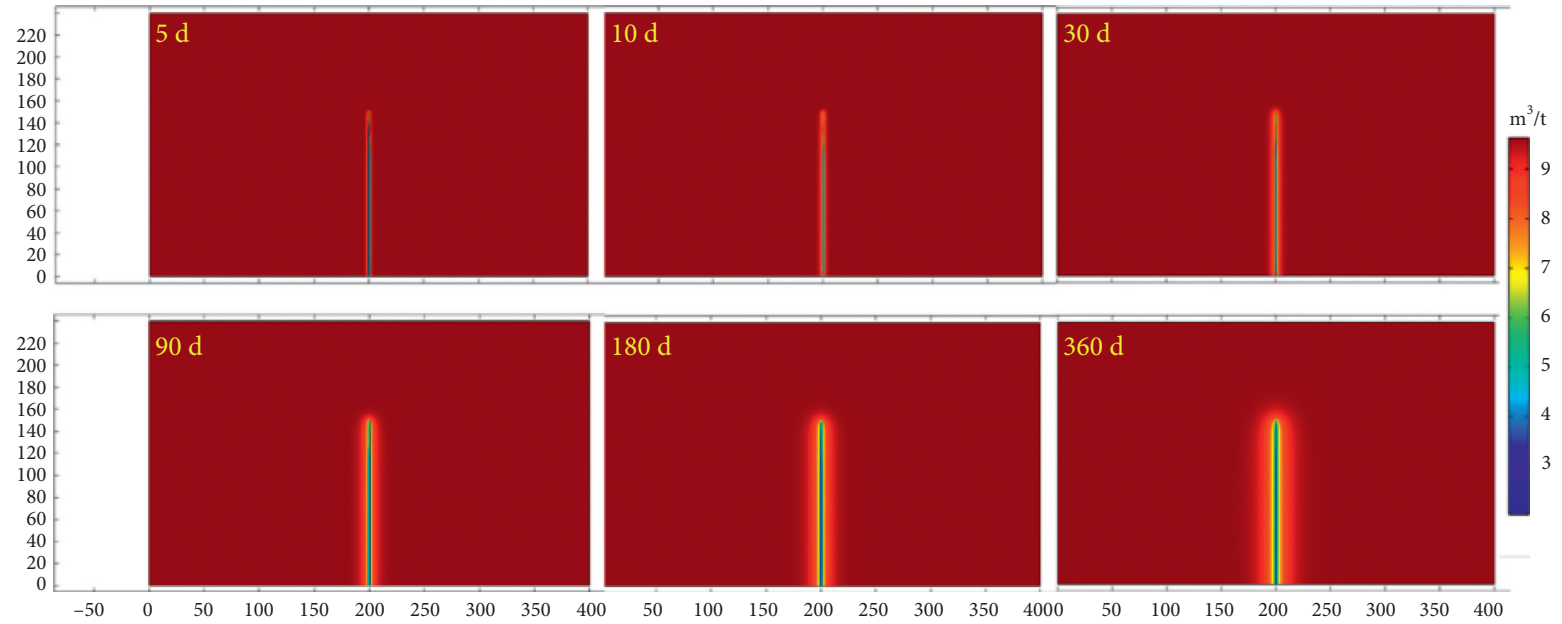

Figure 13: Cloud map of coal seam gas content under different drainage time of 150-meter borehole.

cost. It can be seen that long boreholes along the seam have advantages in all aspects. Therefore, it is recommended that the arrangement of long boreholes along the seam is used in gas drainage in the working face.

\subsection{Influence of Drilling Length on the Effect of Gas Drainage.} To study the impact of the length of the long borehole along the bedding on gas drainage, numerical simulations of gas drainage with borehole lengths of $90 \mathrm{~m}, 120 \mathrm{~m}, 150 \mathrm{~m}$, $180 \mathrm{~m}, 210 \mathrm{~m}$, and $240 \mathrm{~m}$ were carried out. The geometric model is shown in Figure 10.

When the borehole length is $90 \mathrm{~m}$, the gas content distribution around the borehole at different extraction times is shown in Figure 11. It can be seen from Figure 11 that, under the action of the borehole negative pressure, as the drainage time increases, the gas content around the borehole gradually decreases, and the range of influence of borehole drainage gradually increases.

To quantitatively analyze the distribution of gas content around the borehole under different extraction times, a monitoring line is selected along the direction and inclination of the working face, and the gas content change law on it is analyzed. The monitoring line in the strike direction is $45 \mathrm{~m}$ away from the roadway wall, and the monitoring line in the inclined direction is first $5 \mathrm{~m}$ away from the borehole. Figure 12 shows the distribution of gas content on the monitoring line under different extraction times. From Figure 12(a), when the borehole length is $90 \mathrm{~m}$, in the strike direction, as the drainage time increases, the gas content of the coal seam gradually decreases. At a distance of $5 \mathrm{~m}$ from the borehole, the gas content at a drainage time of 180 days is 


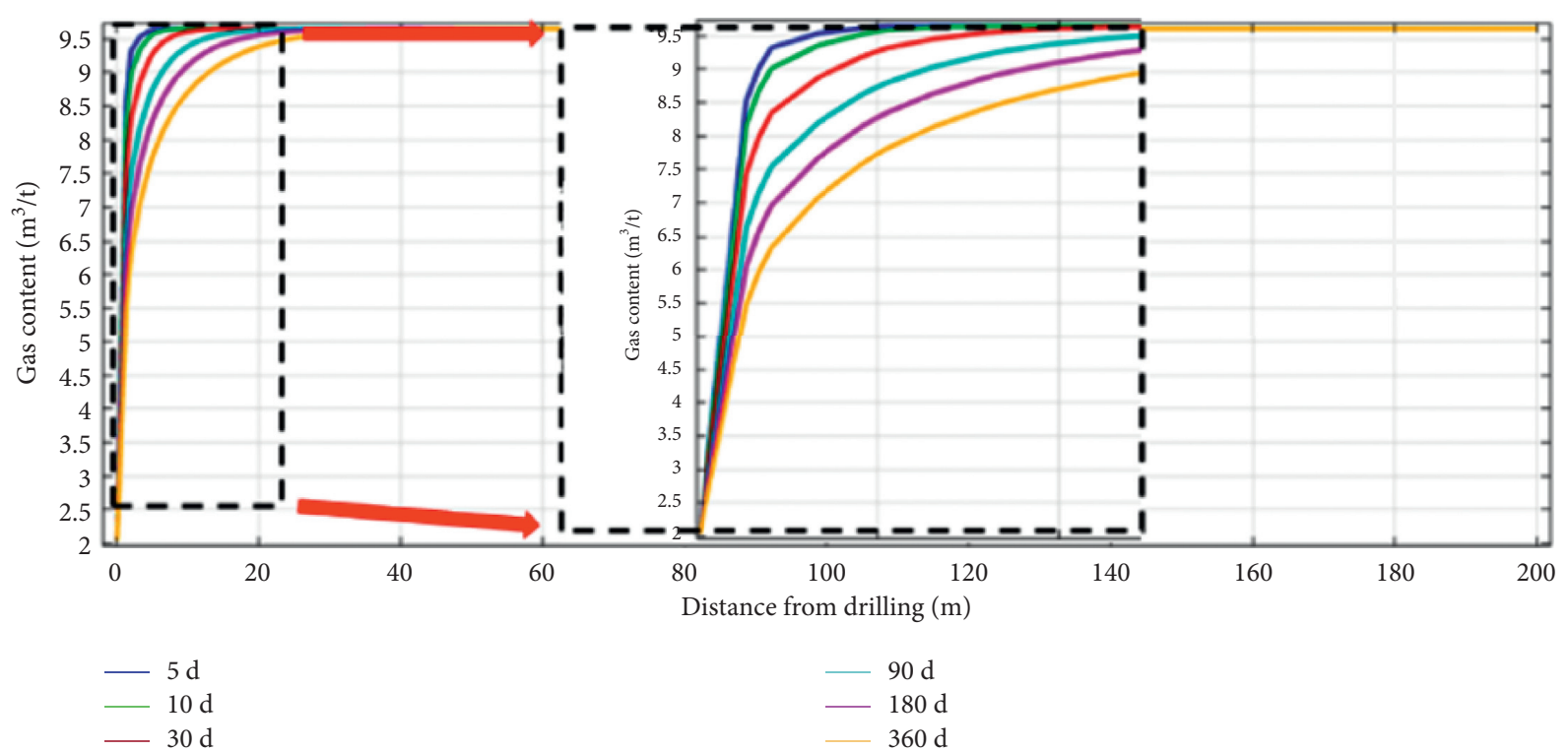

(a)

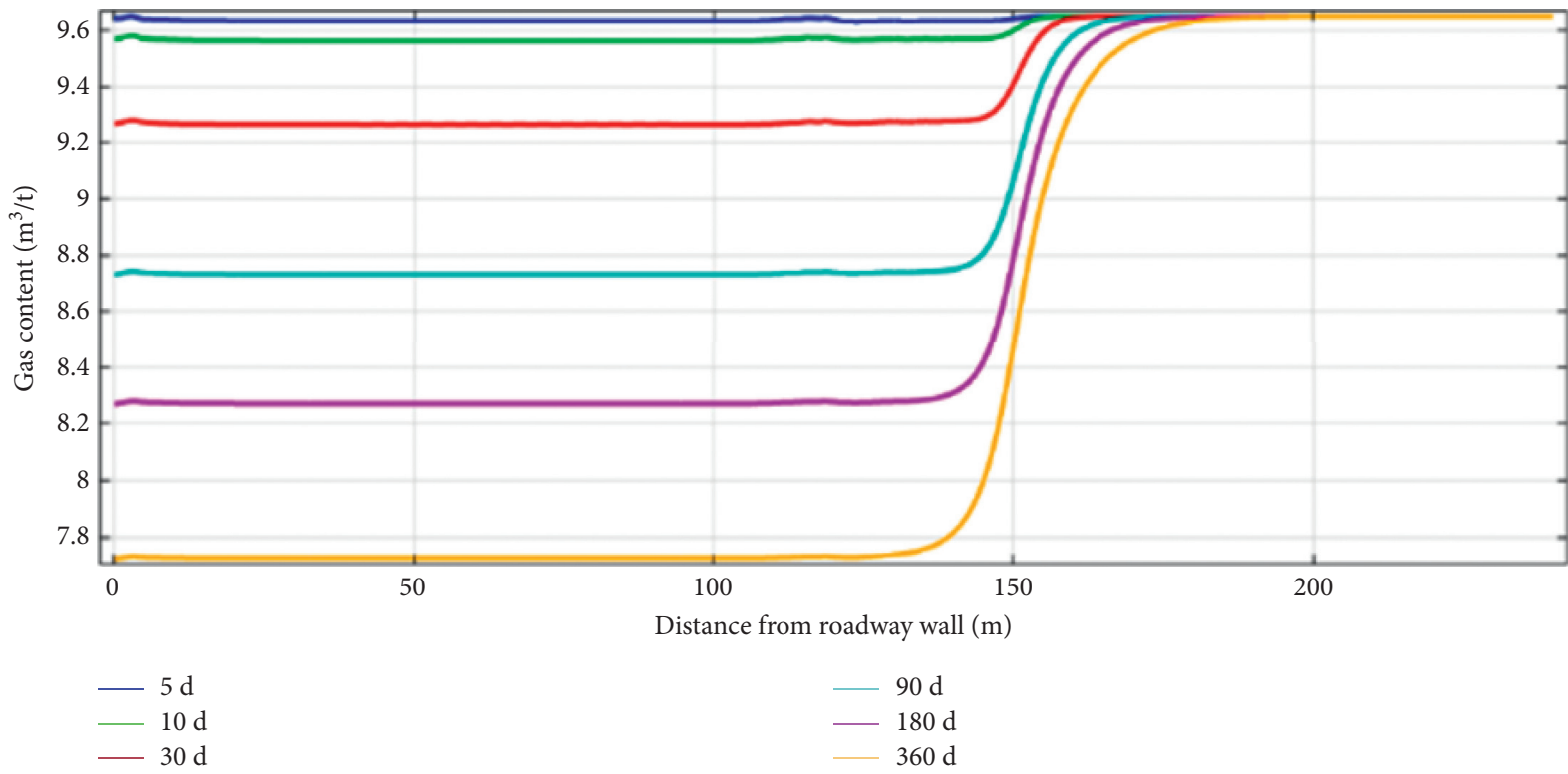

(b)

FIGURE 14: Distribution of gas content in $150 \mathrm{~m}$ borehole with different drainage time: (a) gas content distribution on the monitoring line in the strike direction; (b) distribution of gas content in the trend direction monitoring line.

reduced by $1.0 \mathrm{~m}^{3} / \mathrm{t}$ and $1.3 \mathrm{~m}^{3} / \mathrm{t}$ compared with the gas content at a drainage time of 30 days and five days. In the direction of the trend, the gas content of the coal seam gradually decreases with the increase of the extraction time. However, because the length of the borehole is only $90 \mathrm{~m}$, part of the gas in the middle and back of the coal seam has not been effectively drained.

When the borehole length is $150 \mathrm{~m}$, the gas content distribution around the borehole under different extraction time is shown in Figure 13. It can be seen from Figure 13 that, under the action of borehole negative pressure, as the drainage time increases, the gas content around the borehole gradually decreases, and the range of influence of borehole drainage gradually increases. Compared with the $90 \mathrm{~m}$ borehole, the $150 \mathrm{~m}$ borehole has a broader range of drainage, and the drainage effect is more significant.

In the strike direction, as the drainage time increases, the coal seam gas content gradually decreases. At a distance of $5 \mathrm{~m}$ from the borehole, the gas content at 180-day drainage is reduced by $0.94 \mathrm{~m}^{3} / \mathrm{t}$ and $1.26 \mathrm{~m}^{3} / \mathrm{t}$ compared with the gas content at the drainage time of 30 days and five days, and the change is small compared to the $90 \mathrm{~m}$ borehole, as shown in Figure 14.

When the borehole length is $240 \mathrm{~m}$, the gas content distribution around the borehole under different extraction time is shown in Figure 15. It can be seen from Figure 15 

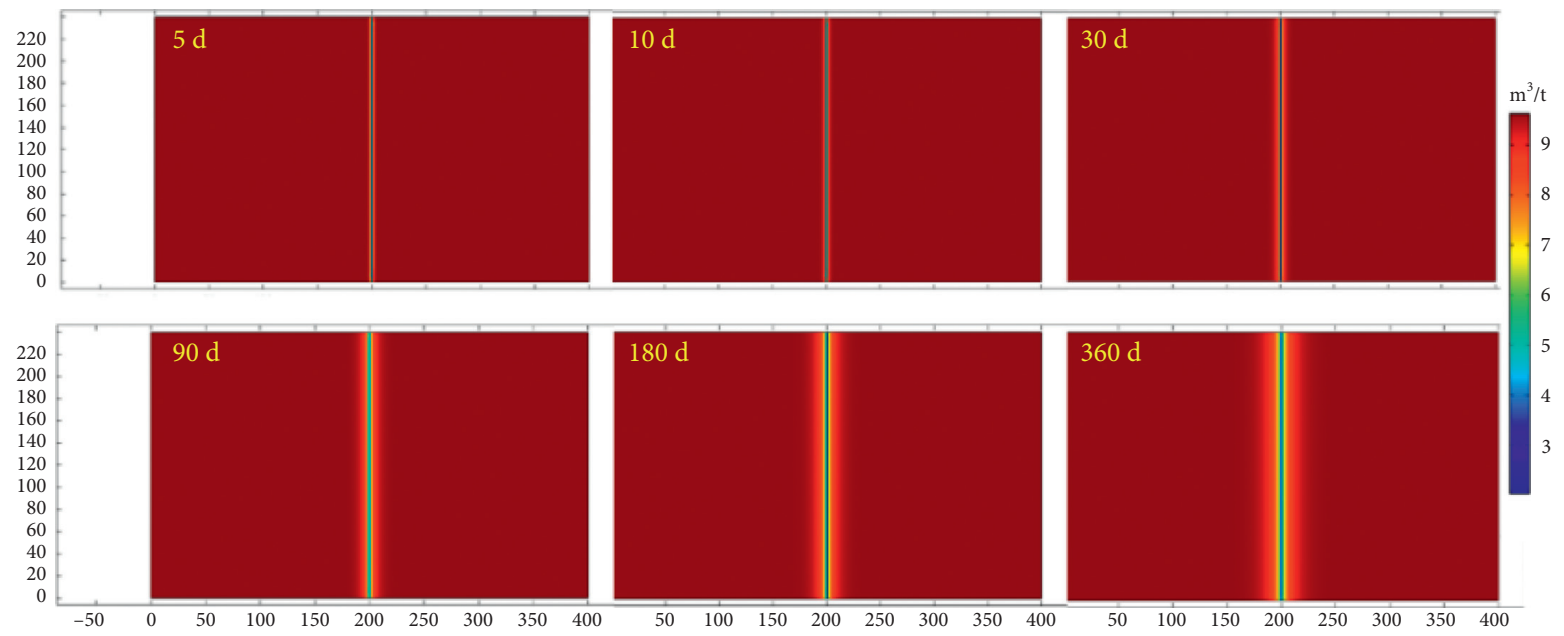

FIgURE 15: Cloud map of coal seam gas content under different drainage time of 240-meter borehole.
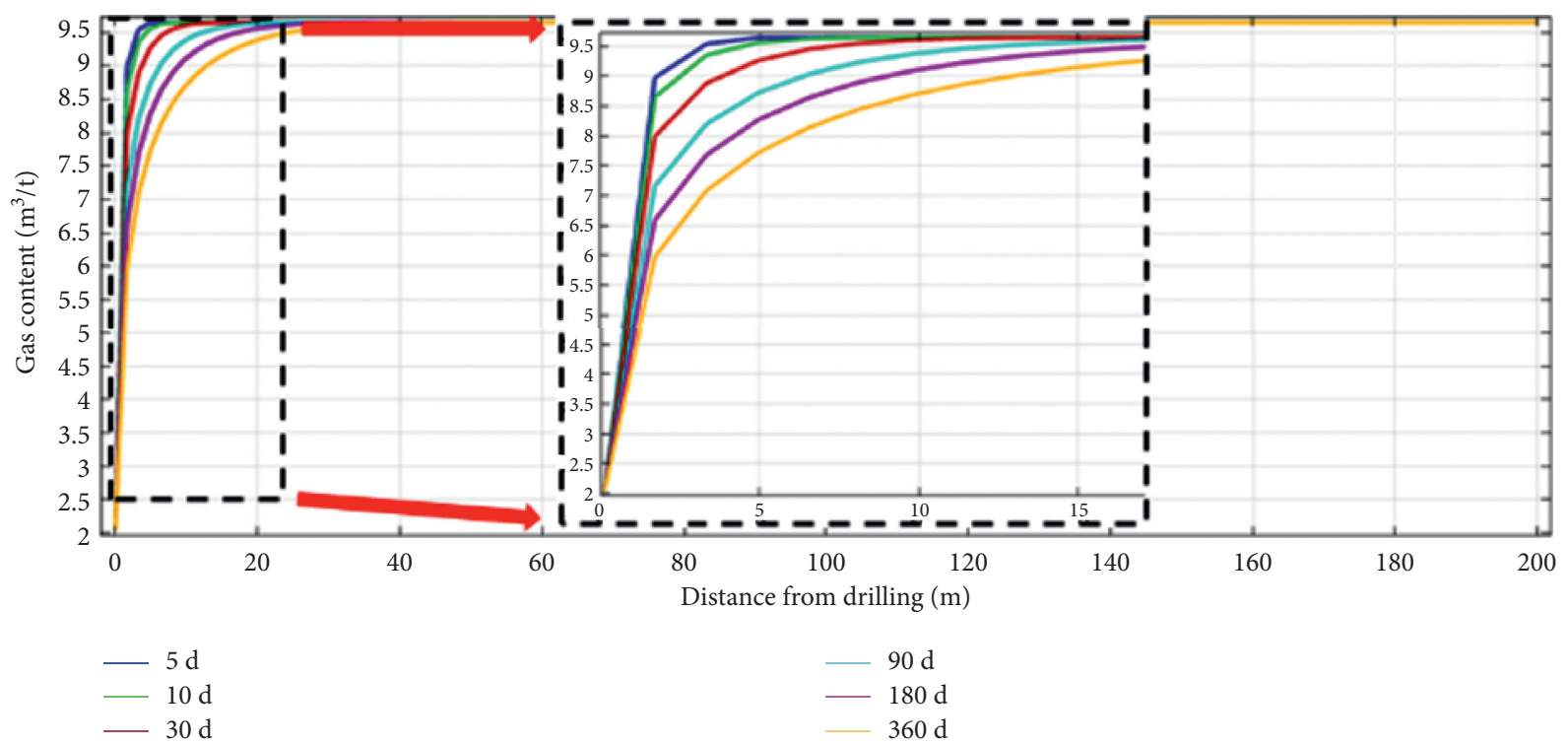

(a)

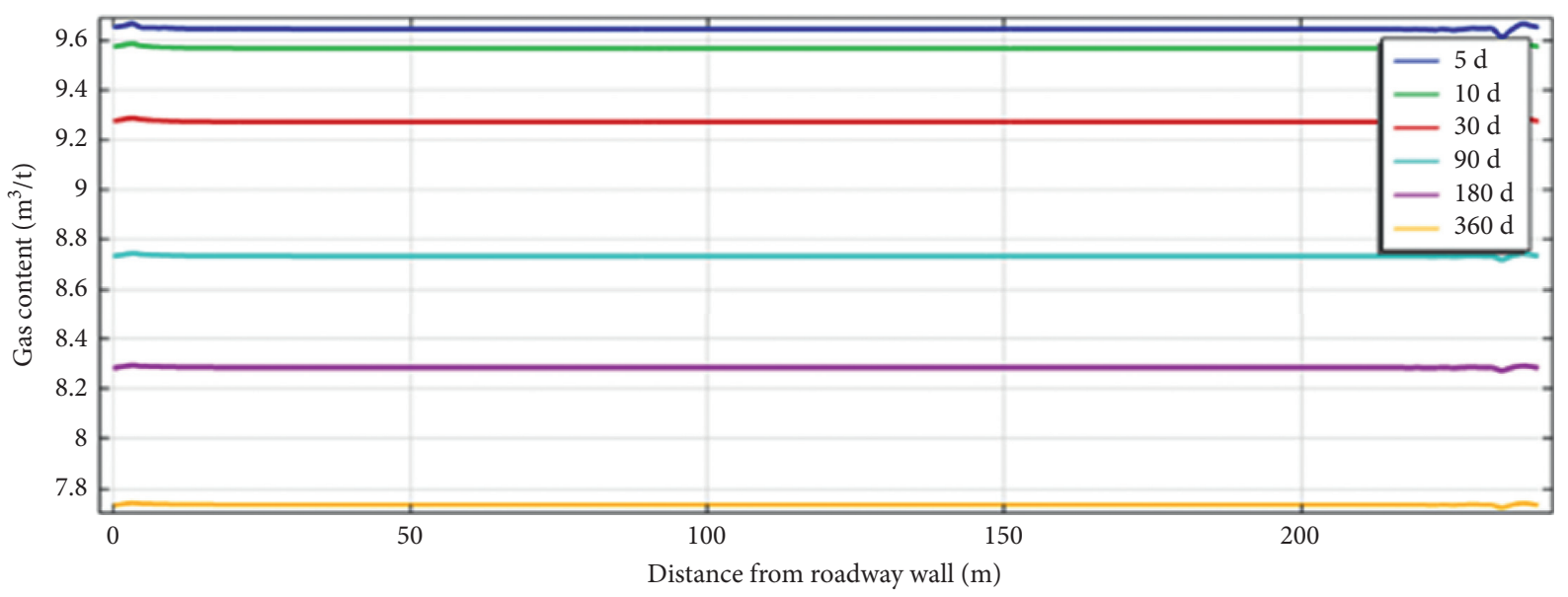

(b)

FIGURE 16: Distribution of gas content in $240 \mathrm{~m}$ borehole with different drainage time: (a) gas content distribution on the monitoring line in the strike direction; (b) distribution of gas content in the trend direction monitoring line. 


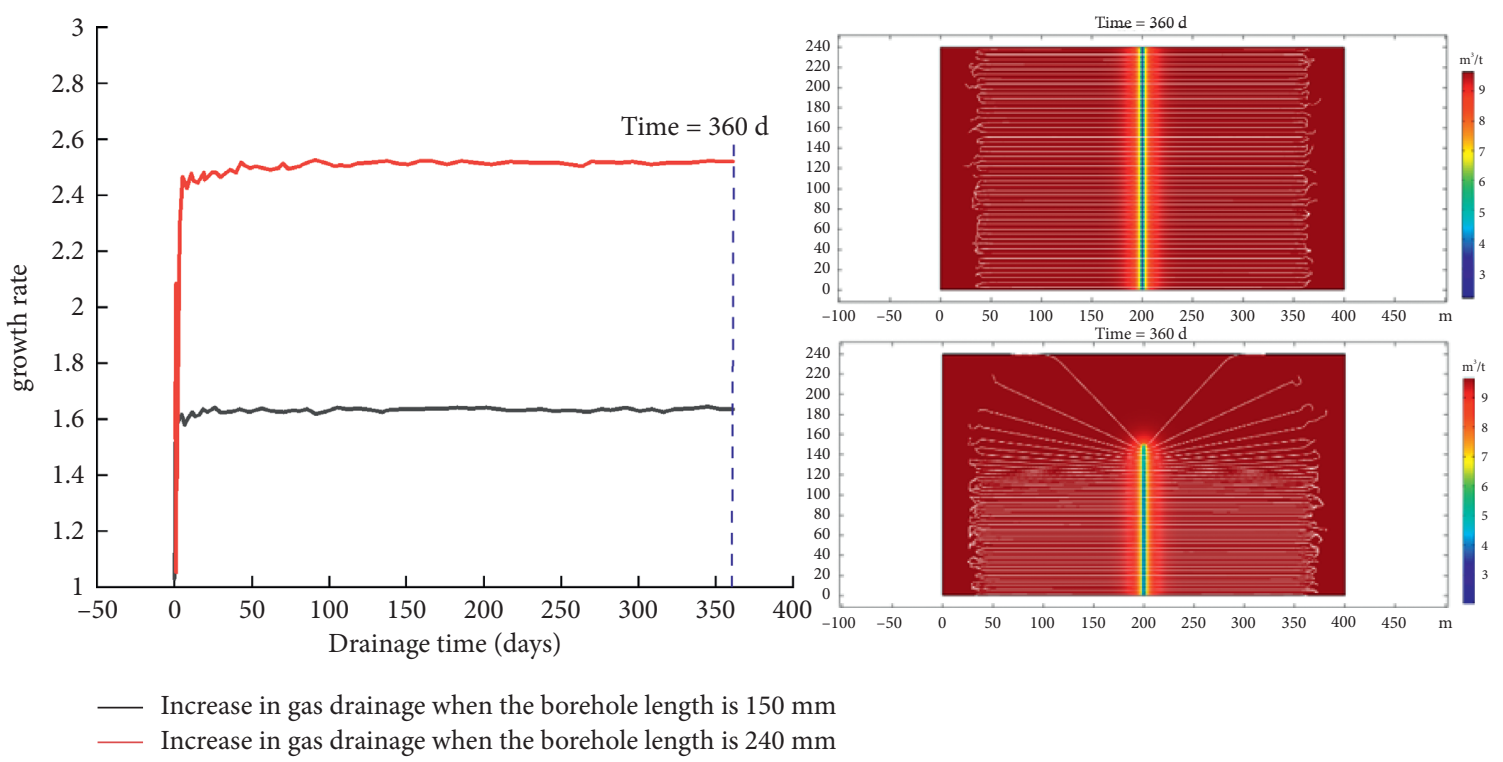

Figure 17: Gas drainage ratio under different borehole lengths.

that, under the action of borehole negative pressure, as the drainage time increases, the gas content around the borehole also shows a gradual decrease, and the influence range of borehole drainage further increases.

In the strike direction, as the drainage time increases, the coal seam gas content gradually decreases. In the trend direction, the gas content in the coal seam gradually decreases with the increase of the extraction time, and the gas content at the bottom of the borehole decreases significantly. With the increase of drilling depth, the upward trend value changes less. As the drilling depth increases, the gas at the bottom of the drilling hole can be drained, and the gas content decreases significantly, as shown in Figure 16.

To quantitatively analyze the impact of borehole length on the gas drainage effect, the drainage volume when the borehole length is $90 \mathrm{~m}$ is used as the benchmark. The increase in the drainage of the $150 \mathrm{~m}$ and $240 \mathrm{~m}$ borehole lengths relative to the $90 \mathrm{~m}$ borehole can be obtained, as shown in Figure 17. It can be seen from Figure 17 that the longer the borehole length, the better the drainage effect and the greater the impact range of the borehole. When the borehole length is $150 \mathrm{~m}$, the drainage volume is about 1.31 times that of the $90 \mathrm{~m}$ borehole; when the borehole length is increased to $240 \mathrm{~m}$, the drainage volume is about 2.50 times that of the $90 \mathrm{~m}$ borehole. It can be seen from Figure 17 that the flow line after drilling is perpendicular to the drilling, the gas migration at the tip of the slot conforms to the law of spherical flow, and the gas migration in the middle and rear parts conforms to the radial flow. With the increase of drilling length, the streamline area and the influence range of drilling increase significantly.

\section{Conclusions}

This paper first elaborates and establishes a multifield coupling model of gas migration in coal. Then, the change value of the residual gas content per unit time is used to quantify the gas drainage effect of the long borehole. Finally, the COMSOL software was adopted to analyze the drainage effects of different layouts and drilling lengths of long boreholes along the bedding. The main conclusions are as follows:

(1) A multifield coupling model for gas-containing coal seams was established. The model considers the gas diffusion in the coal matrix, the gas seepage through fractures, the evolution of permeability, and the deformation of coal. At the same time, the dynamic equation of coal diffusion is introduced to make the simulation results more in line with the actual situation.

(2) By integrating the space of the coupled model and then making the difference in time, the change value of the residual gas content per unit time can be obtained to calculate the gas drainage volume. Furthermore, the gas drainage effect of long boreholes can be quantified.

(3) Under the combined layout of long boreholes along the seam and penetrating boreholes, the gas content of the long boreholes along the seam area is significantly lower than that of the interbedded borehole drainage area.

(4) The drainage volume is similar to that under the combined arrangement under the same drainage time. In the early stage of drainage, the drainage volume under the long borehole layout is 1.025 times that of combined drainage, and it gradually decreases in the later stage, down to 0.94 times at the lowest level.

(5) As the length of the borehole increases, the scope of influence of borehole drainage increases. When the borehole length is $150 \mathrm{~m}$ and $240 \mathrm{~m}$, the drainage volume is about 1.31 and 2.50 times that of the $90 \mathrm{~m}$ borehole. 
The above results provide a particular reference for the layout of long boreholes along the bedding and the determination of reasonable parameters for gas drainage on site.

\section{Data Availability}

All the data, models, and code generated or used during the study appear in the manuscript.

\section{Conflicts of Interest}

The author declares no commercial or associative interest that represents conflicts of interest in connection with the work submitted.

\section{Acknowledgments}

The research presented in this paper was jointly supported by the Natural Science Foundation of Chongqing (Grant No. cstc2020jcyj-msxmX1013).

\section{References}

[1] G. W. Cheng, T. H. Yang, H. Y. Liu et al., "Characteristics of stratum movement induced by downward longwall mining activities in middle-distance multi-seam," International Journal of Rock Mechanics and Mining Sciences, vol. 136, pp. 1365-1609, 2020.

[2] J. Liu, J. Wang, Z. Chen, S. Wang, D. Elsworth, and Y. Jiang, "Impact of transition from local swelling to macro swelling on the evolution of coal permeability," International Journal of Coal Geology, vol. 88, no. 1, pp. 31-40, 2011.

[3] J. Y. Fan, P. Liu, J. J. Li, and D. Jiang, "A coupled methane/ airflow model for coal gas drainage: model development and finite-difference solution," Process Safety and Environmental Protection, vol. 141, pp. 288-304, 2020.

[4] D. L. Fu, G. S. Xu, M. Li et al., "Gas generation from coal: taking Jurassic coal in the Minhe Basin as an example," International Journal of Coal Science \& Technology, vol. 7, no. 3, pp. 611-622, 2020.

[5] G. Z. Hu, J. L. Xu, T. Ren, Y. Dong, W. Qin, and Z Shan, "Field investigation of using water injection through inseam gas drainage boreholes to control coal dust from the longwall face during the influence of abutment pressure," International Journal of Mining, Reclamation and Environment, vol. 30, no. 1, pp. 48-63, 2016.

[6] H. B. Zhao, J. Y. Li, Y. H. Liu, Y. Wang, T. Wang, and H. Cheng, "Experimental and measured research on threedimensional deformation law of gas drainage borehole in coal seam," International Journal of Mining Science and Technology, vol. 30, no. 3, pp. 397-403, 2020.

[7] C. S. Zheng, M. Kizil, Z. W. Chen, and A. Saiied, "Effects of coal damage on permeability and gas drainage performance," International Journal of Mining Science and Technology, vol. 27, no. 5, pp. 783-786, 2017.

[8] Y. Xue, P. G. Ranjith, F. N. Dang, and J. Liu, "Analysis of deformation, permeability, and energy evolution characteristics of coal mass around borehole after excavation," Natural Resources Research, vol. 29, no. 5, pp. 3159-3177, 2020.

[9] F. B. Zhou, T. Q. Xia, X. X. Wang, Y. Zhang, Y. Sun, and J. Liu, "Recent developments in coal mine methane extraction and utilization in China: a review," Journal of Natural Gas Science and Engineering, vol. 31, pp. 437-458, 2016.
[10] J. J. Hu, C. Gao, H. P. Xie, J. Wang, M. Li, and C. Li, “Anisotropic characteristics of the energy index during the shale failure process under triaxial compression," Journal of Natural Gas Science and Engineering, vol. 95, Article ID 104219, 2021.

[11] C. B. Li, D. C. Yang, H. P. Xie, L. Rin, and J. Wang, "Research on the anisotropic fracture behavior and the corresponding fracture surface roughness of shale," Engineering Fracture Mechanics, vol. 255, no. 5, Article ID 107963, 2021.

[12] Y. K. Ma, E. Y. Wang, D. Xiao, and Z. Li, “Acoustic emission generated during the gas sorption-desorption process in coal," International Journal of Mining Science and Technology, vol. 22, no. 3, pp. 391-397, 2012.

[13] S. Harpalani and R. A. Schraufnagel, "Shrinkage of coal matrix with release of gas and its impact on permeability of coal," Fuel, vol. 69, no. 5, pp. 551-556, 1990.

[14] Z. D. Liu, Y. P. Cheng, L. Wang, H. Wang, J. Jiang, and W Li, "Analysis of coal permeability rebound and recovery during methane extraction: implications for carbon dioxide storage capability assessment," Fuel, vol. 230, pp. 298-307, 2018.

[15] E. L. Su, Y. P. Liang, X. Y. Chang, Q. Zou, M. Xu, and A Sasmito, "Effects of cyclic saturation of supercritical CO2 on the pore structures and mechanical properties of bituminous coal: an experimental study," Journal of CO2 Utilization, vol. 40, Article ID 101208, 2020.

[16] Q. Q. Liu, Y. P. Cheng, H. X. Zhou, and P. Guo, "A mathematical model of coupled gas flow and coal deformation with gas diffusion and klinkenberg effects," Rock Mechanics and Rock Engineering, vol. 48, no. 3, pp. 1163-1180, 2015.

[17] E. L. Su, Y. P. Liang, Q. L. Zou, and M. Xu, "Numerical analysis of permeability rebound and recovery during coalbed methane extraction: implications for $\mathrm{CO} 2$ injection methods," Process Safety and Environmental Protection, vol. 149, pp. 93-104, 2021.

[18] J. Dong, Y. P. Cheng, K. Jin et al., "Effects of diffusion and suction negative pressure on coalbed methane extraction and a new measure to increase the methane utilization rate," Fuel, vol. 191, pp. 70-81, 2017.

[19] C. A. Mora and R. A. Wattenbarger, "Analysis and verification of dual porosity and CBM shape factors," Journal of Canadian Petroleum Technology, vol. 48, no. 2, pp. 17-21, 2009.

[20] W. Zhao, K. Wang, R. Zhang, and H. Dong, "Influence of combination forms of intact sub-layer and tectonically deformed sub-layer of coal on the gas drainage performance of boreholes: a numerical study," International Journal of Coal Science \& Technology, vol. 7, no. 3, pp. 571-580, 2020.

[21] T. Liu, B. Q. Lin, and W. Yang, "Impact of matrix-fracture interactions on coal permeability: model development and analysis," Fuel, vol. 207, pp. 522-532, 2017.

[22] T. Liu and B. Q. Lin, "Time-dependent dynamic diffusion processes in coal: model development and analysis," International Journal of Heat and Mass Transfer, vol. 134, pp. 1-9, 2019.

[23] F. B. Zhou, X. X. Wang, and Y. K. Liu, "Gas drainage efficiency: an input-output model for evaluating gas drainage projects," Natural Hazards, vol. 74, no. 2, pp. 989-1005, 2014.

[24] B. Zhang, J. T. Kang, G. X. Kang, and T. Kang, "Molecular dynamics simulations of $\mathrm{CH} 4$ diffusion in kaolinite: influence of water content," International Journal of Coal Science \& Technology, vol. 6, no. 4, pp. 556-563, 2019.

[25] T. Liu, B. Q. Lin, X. H. Fu et al., "Experimental study on gas diffusion dynamics in fractured coal: a better understanding of gas migration in in-situ coal seam," Energy, vol. 195, Article ID 117005, 2020. 
[26] S. C. Wang, F. B. Zhou, C. Liu, and Y. Liu, "Computation model for effective radius of gas-extraction drilling in coal mine," Disaster Advances, vol. 5, no. 4, pp. 693-697, 2012.

[27] C. L. Zhang, J. Xu, S. J. Peng, Q. Li, and F. Yan, "Experimental study of drainage radius considering borehole interaction based on 3D monitoring of gas pressure in coal," Fuel, vol. 239, pp. 955-963, 2019.

[28] J. Wang, L. Tang, G. Ding, and C. Su, "Mathnatical description of gas drainage radius for underground gas storage," Chemistry and Technology of Fuels and Oils, vol. 54, no. 4, pp. 500-508, 2018.

[29] H. F. Lin, M. Huang, S. G. Li, and C. Zhang, "Numerical simulation of influence of Langmuir adsorption constant on gas drainage radius of drilling in coal seam," International Journal of Mining Science and Technology, vol. 26, no. 3, pp. 377-382, 2016

[30] I. Palmer and J. Mansoori, "How permeability depends on stress and pore pressure in coalbeds: a new model," $S P E$ Reservoir Evaluation and Engineering, vol. 1, no. 6, pp. 539544, 1998.

[31] T. Liu, J. B. Q. Lin, W. Yang et al., "Dynamic diffusion-based multifield coupling model for gas drainage," Journal of Natural Gas Science and Engineering, vol. 44, pp. 233-249, 2017.

[32] Z. J. Pan and L. D. Connell, "Modelling permeability for coal reservoirs: a review of analytical models and testing data," International Journal of Coal Geology, vol. 92, pp. 1-44, 2012.

[33] E. L. Su, Y. P. Liang, Q. L. Zou, F Niu, and L Li, "Analysis of effects of $\mathrm{CO} 2$ injection on coalbed permeability: implications for coal seam CO2 sequestration," Energy \& Fuels, vol. 33, no. 7, pp. 6606-6615, 2019. 